\title{
LETTERS
}

\section{Consider the full spectrum of household food insecurity}

Public policy positions breastfeeding as a key strategy to protect vulnerable children from household food insecurity. ${ }^{1,2}$ Using data from a Canadian populationrepresentative survey, Orr and colleagues report that household food insecurity negatively affects the duration of exclusive breastfeeding. ${ }^{3}$ They show that mothers with severe household food insecurity breastfeed for a significantly shorter time than mothers in food-secure households or in marginally and moderately foodinsecure households. However, among Inuit mothers in Canada with a high prevalence of household food insecurity, this difference does not seem to be apparent. ${ }^{4}$

In emerging nations, widespread poverty often results in extreme household food insecurity, which, in contrast to households in developed nations, may lead to exclusive breastfeeding by way of "last resort exclusive breastfeeding." 5 Mothers practise exclusive breastfeeding because they have no alternative food source for their infants. ${ }^{5}$ Nevertheless, they may have perceptions of breast milk insufficiency and feelings of weakness. ${ }^{6}$ These polar differences may reflect the spectrum for household food insecurity, from marginal to severe and extreme, that may not be captured in categorical data collection.

The findings of Orr and colleagues reinforce prior impressions that a breastfeeding paradox exists, whereby "women who can least afford to buy infant formula and whose infants can benefit most from the health-promoting qualities of breast milk are the least likely to breastfeed." ${ }^{1,2}$ Recognition of the full spectrum of household food insecurity needs incorporation into policies and programs that may strengthen food security and support mother and child nutrition.

\section{Peter D. Wong MD MPH}

Associate professor, Division of Paediatric Medicine, Department of Paediatrics, Faculty of Medicine, University of Toronto, Ont.

\section{Sharon H. Thadani}

Research assistant, TARGetKids!, St. Michael's Hospital, Toronto, Ont.

\section{Laura L. Brown MD}

Assistant professor, Department of Pediatrics, University of Utah School of Medicine, Salt Lake City, Utah

\section{Rosemary G. Moodie MD MBA}

Associate professor, Division of Neonatology, Department of Paediatrics, Faculty of Medicine, University of Toronto, Ont.

- Cite as: CMAJ 2019 January 7;191:E20. doi: $10.1503 / \mathrm{cmaj} .69952$

\section{References}

1. Venu I, van den Heuvel M, Wong JP, et al. The breastfeeding paradox: relevance for household food insecurity. Paediatr Child Health 2017;22: 180-3.

2. Frank $L$. The breastfeeding paradox: a critique of policy related to infant food insecurity in Canada. Food Cult Soc 2015;18:107-29.

3. Orr SK, Dachner N, Frank L, et al. Relation between household food insecurity and breastfeeding in Canada. CMAJ 2018;190:E312-9.

4. Mclsaac KE, Stock DC, Lou W. Household food security and breast-feeding duration among Canadian Inuit. Public Health Nutr 2017;20:64-71.

5. Lesorogol C, Bond C, Dulience SJL, et al. Economic determinants of breastfeeding in Haiti: The effects of poverty, food insecurity, and employment on exclusive breastfeeding in an urban population. Matern Child Nutr 2018;14:e12524.

6. Webb-Girard A, Cherobon A, Mbugua S, et al. Food insecurity is associated with attitudes towards exclusive breastfeeding among women in urban Kenya. Matern Child Nutr 2012;8:199-214.

Competing interests: None declared. 